\title{
Increased risk of second malignancies after in situ breast carcinoma in a population-based registry
}

\author{
I Soerjomataram ${ }^{*, 1}$, WJ Louwman ${ }^{2}$, MJC van der Sangen ${ }^{3}$, RMH Roumen ${ }^{4}$ and JWW Coebergh ${ }^{1,2}$ \\ 'Department of Public Health, Erasmus MC, PO Box 2040, Rotterdam 3000 CA, The Netherlands; ${ }^{2}$ Comprehensive Cancer Centre South, PO Box 231 , \\ Eindhoven 5600 AE, The Netherlands; ${ }^{3}$ Department of Radiotherapy, Catharina Hospital, PO Box 1350, Eindhoven 5602 ZA, The Netherlands; \\ ${ }^{4}$ Department of Surgery, Maxima Medisch Centrum, PO Box 7777, Veldhoven 5500 MB, The Netherlands
}

Among 1276 primary breast carcinoma in situ (BCIS) patients diagnosed in 1972-2002 in the Southern Netherlands, I I\% developed a second cancer. Breast carcinoma in situ patients exhibited a two-fold increased risk of second cancer (standardised incidence ratios (SIR): 2. I, 95\% confidence interval (CI): I.7-2.5). The risk was highest for a second breast cancer (SIR: 3.4, 95\% Cl: 2.6-4.3; AER: 66 patients per 10000 per year) followed by skin cancer (SIR: I.7, 95\% Cl: I.I -2.6; AER: I7 patients per 10000 per year). The increased risk of second breast cancer was similar for the ipsilateral (SIR: 1.9, 95\% Cl: 1.3-2.7) and contralateral (SIR: 2.0, 95\% Cl: 1.4-2.8) breast. Risk of second cancer was independent of age at diagnosis, type of initial therapy, histologic type of BCIS and period of diagnosis. Standardised incidence ratios of second cancer after BCIS (SIR: 2.3, 95\% Cl: 1.8-2.8) resembled that after invasive breast cancer (SIR: 2.2, 95\% Cl: 2.I-2.4). Surveillance should be directed towards second (ipsi- and contra-lateral) breast cancer. British Journal of Cancer (2006) 95, 393-397. doi:I0.1038/sj.bjc.660323I www.bjcancer.com

Published online 27 June 2006

(c) 2006 Cancer Research UK

Keywords: breast carcinoma in situ; population-based; risk; second cancer

Diagnosis of ductal breast carcinoma in situ has increased in the Netherlands, partly as a consequence of screening (Fracheboud et al, 2004), from 0.3 per 100000 in 1975 to 13.4 per 100000 in 1997 (Voogd et al, 2000). Women with previous breast cancer are known to carry a two-fold increased risk of second cancer in comparison to the general population (Rubino et al, 2003; Soerjomataram et al, 2005a). Studies assessing the risk of second cancer following the diagnosis of BCIS (breast carcinoma in situ) are however scarce or only focused on the risk of second breast cancer (Habel et al, 1997; Warnberg et al, 2000; Claus et al, 2003; Levi et al, 2005; Rawal et al, 2005).

An increased risk of 2.0-7.2 for breast cancer following the diagnosis of BCIS has been reported (Franceschi et al, 1998; Rawal et al, 2005), the probability that a breast cancer will develop in BCIS patients being $26 \%$ after 20 years of follow-up (Levi et al, 2005). This is as high as the risk of second breast cancer found for patients with malignant breast carcinoma (Chen et al, 2001). Excess risk of second breast cancer is not explained by treatment choice (i.e. radiotherapy) for BCIS (Claus et al, 2003), suggesting a shared aetiology (hereditary or lifestyle) for both first and second cancer. In addition to second breast cancer, other cancers were diagnosed in $17 \%$ of DCIS and $3.2 \%$ of lobular carcinoma in situ (LCIS) patients (Ward et al, 1992). However, no previous studies assessed the risks of different types of second cancer in BCIS patients.

The aim of the study is to assess the risk pattern for second cancer after diagnosis of BCIS and to compare it with that found

\footnotetext{
*Correspondence: Dr I Soerjomataram;

E-mail: i.soerjomataram@erasmusmc.nl

Revised 25 May 2006; accepted 31 May 2006; published online 27 June 2006
}

for malignant breast carcinoma, thereby examining the impact of age, breast cancer screening policy at the time of primary BCIS diagnosis and treatment for various subtypes of BCIS.

\section{MATERIALS AND METHODS}

\section{Data collection}

Data were obtained from the population-based ECR (Eindhoven Cancer Registry) in the Southern Netherlands, covering 2.4 million inhabitants in 2004. The cancer registry is notified of newly diagnosed cases by the pathology departments in the region. In addition, lists of all hospitalised cancer patients were obtained. Active follow-up of vital status was conducted through the Central Bureau for Genealogy that receives data from municipal population registries. In the ECR, any new tumour, not classified as a recurrence or direct extension of a previously known tumour, is recorded as a new primary tumour. This registry also records incidence data on first basal cell carcinoma (BCC) of the skin. A detailed description of the data collection has been presented elsewhere (Soerjomataram et al, 2005a).

\section{Study population}

We identified 1402 women older than 25 years diagnosed with in situ breast cancer (ICD-O behaviour code/2) from 1 January 1972 through 31 December 2002. Among patients eligible for the study, those with less than 1-year follow-up time $(n=174)$ and those with unknown morphological code $(n=5)$ were excluded. End of follow-up was 31 December 2003, date of death, date of last followup or date of second cancer diagnosis, whichever occurred first. 
Thus, 1223 women remained for analysis, 143 of whom $(11.2 \%)$ developed a second cancer, $170(13.3 \%)$ died and $2(0.2 \%)$ were lost to follow-up. The maximum follow-up time was of 32 years.

\section{Statistical methods}

We calculated standardised incidence ratios (SIRs) to measure the relative risk of developing second tumours by comparing the incidence of second cancer among patients with a diagnosis of BCIS to the incidence of similar cancer in the general population. We adjusted for age (in 5-year categories) and calendar year of BCIS diagnosis. The 95\% confidence intervals (95\% CI) were calculated using exact Poisson probability (Breslow and Day, 1987). We also calculated the absolute excess risk (AER) examining the excess incidence of second cancers per 10000 patients in each year (van Leeuwen and Travis, 2005). Furthermore, the cumulative risk of developing second cancer, which is the proportion of patients alive at time $t$ who can be expected to develop a second cancer, was calculated using the life table method (Cutler and Ederer, 1958).

The following categorisation of BCIS histological type was made; LCIS (ICD-O 8520/2) and DCIS including Paget's disease (ICD-O $8500 / 2,8010 / 2,8050 / 2,8140 / 2,8201 / 2,8230 / 1,8501 / 2,8503 / 2$, $8504 / 2,8507 / 2,8521 / 1,8523 / 2,8540 / 2$ ) (Vereniging van Integrale Kankercentra, 2005). Year 1993 was considered the starting point of breast cancer screening, which was fully implemented in 1996 (Fracheboud et al, 1998, 2004). Calculation of risk for the ipsilateral and contralateral second breast cancer was performed using only patients with information on laterality of first BCIS and second breast cancer (excluded for this analysis $n=52$ ).

Standardised incidence ratios for selected cancers after malignant breast cancer were obtained from a previous study performed in ECR (Soerjomataram et al, 2005a) and compared with that of BCIS in the current study. In the earlier study, we estimated the risk of subsequent cancers in 9919 women diagnosed with malignant breast cancers in 1972-2000 followed until 2001. To allow comparison, we added second nonmelanotic skin cancer cases (BCC: 192 and squamous cell carcinoma: 42) for the analysis of second skin cancer. We used a similar method to calculate SIRs and 95\% confidence intervals as explained before. A detailed description of this study has been described elsewhere (Soerjomataram et al, 2005a).

All statistical analyses were performed using SPSS 11.5 for Windows (Statistical Products and Service Solution, Inc., Chicago, IL, USA).

\section{RESULTS}

The mean follow-up time for the cohort was 6.3 years. A large proportion of BCIS patients was older than 50 years and was diagnosed with DCIS (95\%) in 1993-2002 (Table 1).

Table 2 shows the SIRs and AERs for second breast and other cancers. We found an increased risk of second breast cancer (SIR 2.1, 95\% CI: 1.7-2.5) and other non-breast cancers (SIR: 1.4, 95\% CI: $1.1-1.9)$. An excess of 66 patients with second breast cancer for every 10000 BCIS patients per year was observed. An increased risk of second breast cancer was found for both the ipsilateral (SIR: 1.9, 95\% CI: $1.3-2.7$ ) and contralateral breast (SIR: 2.0, 95\% CI: 1.4-2.8). Almost a two-fold elevated risk of skin cancer (SIR: 1.7, 95\% CI: $1.1-2.5)$ was found.

A three- to four-fold increased risk of second breast cancer was found during the first 10 years of follow-up (Table 3), which was relatively higher than the SIR for the last follow-up period $(\geqslant 10$ years). As for the risk of second non-breast cancer, we observed similar SIRs across all follow-up periods.

Increased risks of second breast or other cancers were not influenced by age at BCIS diagnosis, type of initial therapy,
Table I Characteristics at diagnosis of BCIS (breast carcinoma in situ) ${ }^{\mathrm{a}}$

\begin{tabular}{|c|c|c|c|}
\hline & \multicolumn{2}{|c|}{ Subsequent cancer } & \multirow[b]{2}{*}{ Total (\%) } \\
\hline & No. (\%) & Yes (\%) & \\
\hline \multicolumn{4}{|l|}{ Age at BCIS diagnosis } \\
\hline$\leqslant 49$ years & $288(26)$ & $30(27)$ & $318(26)$ \\
\hline$\geqslant 50$ years & $822(74)$ & $83(73)$ & $905(74)$ \\
\hline \multicolumn{4}{|l|}{ Initial treatment } \\
\hline No radiotherapy & $765(69)$ & $68(60)$ & $833(68)$ \\
\hline With radiotherapy & $345(31)$ & $45(40)$ & $390(32)$ \\
\hline \multicolumn{4}{|l|}{ Follow-up } \\
\hline $1-4$ years & 549 (49) & $64(57)$ & $613(50)$ \\
\hline $5-9$ years & $396(36)$ & $34(30)$ & $430(35)$ \\
\hline$\geqslant 10$ years & $165(15)$ & $15(13)$ & $180(15)$ \\
\hline \multicolumn{4}{|l|}{ Subtype of initial cancer } \\
\hline DCIS & $1052(95)$ & 105 (93) & $1157(95)$ \\
\hline $\mathrm{LCIS}^{\mathrm{C}}$ & $58(5)$ & $8(7)$ & $66(5)$ \\
\hline \multicolumn{4}{|l|}{ Time of diagnosis ${ }^{\mathrm{d}}$} \\
\hline $1972-1992$ & $165(15)$ & $41(36)$ & $206(17)$ \\
\hline $1993-2002$ & $945(85)$ & $72(64)$ & $1017(83)$ \\
\hline Total & 1110 & 113 & $1223(100)$ \\
\hline
\end{tabular}

${ }^{\mathrm{a}}$ Mean age at $\mathrm{BCIS}$ diagnosis $=57.1$ years; Mean follow-up time $=6.3$ years ${ }^{\mathrm{b}} \mathrm{DCIS}$ ductal carcinoma in situ. ' LCIS: lobular carcinoma in situ. ${ }^{\mathrm{d} B r e a s t}$ cancer screening in southern Netherlands began to have impact in 1993 (Fracheboud et al, 2004).

Table 2 Standardised incidence ratio (SIR) and absolute excess risk (AER) for all second cancers diagnosed in 1972-2003 following BCIS (breast carcinoma in situ) in southern Netherlands

Relative and absolute risks ${ }^{\mathrm{a}}$

Site of second cancer Observed Expected SIR $95 \% \mathrm{CI}$ AER

\begin{tabular}{|c|c|c|c|c|c|}
\hline $\begin{array}{l}\text { All sites } \\
\text { All sites excluding breast }{ }^{c}\end{array}$ & $\begin{array}{r}113 \\
52\end{array}$ & $\begin{array}{l}54.4 \\
36.2\end{array}$ & $\begin{array}{l}2.1^{\mathrm{b}} \\
1.4^{\mathrm{b}}\end{array}$ & $\begin{array}{l}1.7-2.5 \\
1.1-1.9\end{array}$ & $\begin{array}{l}90 \\
24\end{array}$ \\
\hline $\begin{array}{l}\text { Digestive tract }{ }^{\mathrm{d}} \\
\text { Stomach } \\
\text { Colon }\end{array}$ & $\begin{array}{r}11 \\
3 \\
6\end{array}$ & $\begin{array}{r}10.4 \\
1.6 \\
5.2\end{array}$ & $\begin{array}{l}1.1 \\
1.8 \\
1.2\end{array}$ & $\begin{array}{l}0.5-1.9 \\
0.4-5.3 \\
0.4-2.5\end{array}$ & $\begin{array}{l}1 \\
2 \\
1\end{array}$ \\
\hline $\begin{array}{l}\text { Lung } \\
\text { Skin } \\
\text { Melanoma } \\
\text { Basal cell carcinoma }\end{array}$ & $\begin{array}{r}5 \\
27 \\
4 \\
22\end{array}$ & $\begin{array}{r}3.5 \\
15.8 \\
1.4 \\
12.8\end{array}$ & $\begin{array}{l}1.4 \\
1.7^{\mathrm{b}} \\
3.0 \\
1.7^{\mathrm{b}}\end{array}$ & $\begin{array}{l}0.5-3.3 \\
1.1-2.5 \\
0.8-7.6 \\
1.1-2.6\end{array}$ & $\begin{array}{r}2 \\
17 \\
4 \\
14\end{array}$ \\
\hline $\begin{array}{l}\text { Breast } \\
\left.\quad\right|^{\text {|psilateral| }} \\
\text { Contralateral }^{\mathrm{f}}\end{array}$ & $\begin{array}{l}61 \\
29 \\
31\end{array}$ & $\begin{array}{l}18.1 \\
15.5 \\
15.5\end{array}$ & $\begin{array}{l}3.4^{\mathrm{b}} \\
1.9^{\mathrm{b}} \\
2.0^{\mathrm{b}}\end{array}$ & $\begin{array}{l}2.6-4.3 \\
1.3-2.7 \\
1.4-2.8\end{array}$ & $\begin{array}{l}66 \\
24 \\
28\end{array}$ \\
\hline $\begin{array}{l}\text { Urogenital tract }{ }^{g} \\
\text { Ovary }\end{array}$ & $\begin{array}{l}4 \\
2\end{array}$ & $\begin{array}{l}7.1 \\
2.5\end{array}$ & $\begin{array}{l}0.6 \\
0.8\end{array}$ & $\begin{array}{l}0.2-1.4 \\
0.1-2.8\end{array}$ & $\begin{array}{l}-5 \\
-1\end{array}$ \\
\hline Lymphoma and multiple myeloma & 2 & 2.5 & 0.8 & $0.1-2.9$ & -1 \\
\hline
\end{tabular}

${ }^{a}$ Excluding patients with less than I-year follow-up. ${ }^{\text {b } 95 \%}$ confidence interval excludes

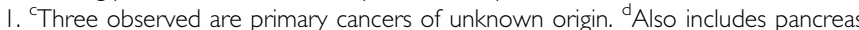
$[\mathrm{I}]$ and rectum [I]. ${ }^{\mathrm{e} A l s o}$ includes squamous cell carcinoma of the skin [I] ${ }^{\mathrm{f}}$ Only includes patients with known laterality of BCIS and second breast cancer. ${ }^{g} \mathrm{Also}$ includes corpus uteri $[\mathrm{I}]$ and bladder $[\mathrm{I}]$.

histological type of BCIS and time of BCIS diagnosis (Table 4). Ipsi- and contra-lateral invasive breast cancer risks were slightly higher for BCIS patients who received radiotherapy (SIR: $2.1,95 \%$ CI: $1.0-4.0$ and SIR: $2.4,95 \%$ CI: $1.2-4.3$, respectively), compared 
Table 3 Standardised incidence ratio (SIR) and absolute excess risk (AER) for second breast cancer and second other cancers after BCIS (breast carcinoma in situ), according to follow-up time

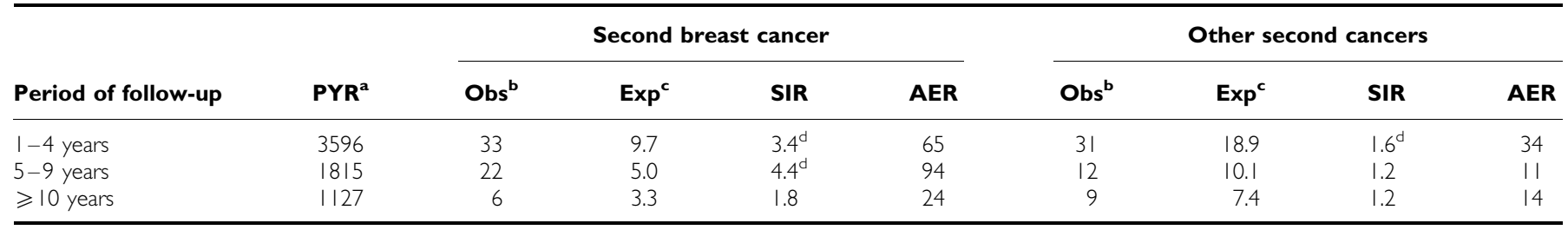

aPYR: person-years. ${ }^{b}$ Obs: observed numbers of second primary cancers. ${ }^{c}$ Exp: expected numbers of second primary cancers. ${ }^{d} 95 \%$ confidence interval excludes 1.

Table 4 Standardised incidence ratio (SIR) and absolute excess risk (AER) for all second cancers diagnosed I972-2003 following BCIS (breast carcinoma in situ) in southern Netherlands, according to women's characteristics at the time of BCIS diagnosis

\begin{tabular}{|c|c|c|c|c|c|c|c|c|c|}
\hline Characteristic & PYR $^{\mathbf{a}}$ & \multicolumn{4}{|c|}{ Second breast cancer } & \multicolumn{4}{|c|}{ Second other cancers } \\
\hline \multicolumn{10}{|l|}{ Age at diagnosis } \\
\hline$\leqslant 49$ years & 2334 & 20 & 4.9 & $4.0^{d}$ & 65 & 10 & 6.6 & 1.5 & 15 \\
\hline$\geqslant 50$ years & 4204 & 41 & 13.1 & $3.1^{d}$ & 66 & 42 & 29.8 & $1.4^{\mathrm{d}}$ & 29 \\
\hline \multicolumn{10}{|l|}{ Treatment } \\
\hline \multicolumn{10}{|l|}{ Subtype of initial cancer } \\
\hline DCIS & 6106 & 58 & 16.8 & $3.4^{\mathrm{d}}$ & 67 & 47 & 34.3 & $1.4^{\mathrm{d}}$ & 21 \\
\hline LCIS & 432 & 3 & 1.2 & 2.5 & 42 & 5 & 2.1 & 2.4 & 67 \\
\hline \multicolumn{10}{|l|}{ Time of diagnosis ${ }^{\mathrm{e}}$} \\
\hline $1972-1992$ & 2708 & 24 & 7.0 & $3.4^{\mathrm{d}}$ & 63 & 17 & 14.4 & 1.2 & 9 \\
\hline
\end{tabular}

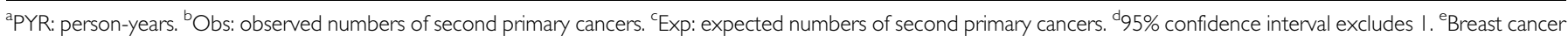
screening in southern Netherlands began to have impact in 1993 (Fracheboud et al, 2004).

to patients who did not receive radiotherapy (SIR: $1.7,95 \% \mathrm{CI}$ : $1.1-2.8$ and SIR: $1.8,95 \%$ CI: $1.1-2.8)$. The cumulative 10 -year risk of developing any second cancer was $17 \%( \pm 5 \%)$, whereas the 15 -year corresponding risk was $21 \%( \pm 8 \%)$ (Figure 1 ).

Figure 2 compares the SIRs for second cancer after BCIS with those after invasive breast cancer for selected malignancies. The SIRs for second cancer of the lung, colon, skin and breast after BCIS were similar to those after invasive breast cancer. The risk pattern of second cancer at all sites after BCIS (SIR: 2.3, 95\% CI: $1.8-2.8$ ) was similar to that of second cancer after invasive breast cancer (SIR: $2.2,95 \%$ CI: $2.1-2.4$ ).

\section{DISCUSSION}

Women previously diagnosed with in situ breast carcinoma had an increased risk of second cancer, in particular second breast and skin cancer. An excess of 90 second cancers per 10000 BCIS patients was found. Similar to previous studies (Franceschi et al, 1998), we observed a $21 \%$ increased risk for a second cancer after 15 years of survival.

Some limitations of our study should be considered. Firstly, as most women were diagnosed after 1993, the majority had less than 10 years of follow-up. Furthermore, the absolute numbers of our study is relatively small. Thus, we may not have estimated correctly the long-term risk of less common cancers such as ovarian cancer, which exhibits an increased risk among long-term survivors of invasive breast cancer (Soerjomataram et al, 2005b). Secondly, increased medical surveillance of women with a diagnosis of BCIS may have increased detection of second cancers (van Leeuwen and
Travis, 2005). In our cohort, 60\% (30 patients) were diagnosed with second cancer within the first year after BCIS diagnosis. Therefore, we excluded patients with less than 1-year of follow-up and those with a second carcinoma in situ. Thirdly, AER in this article should be interpreted with caution because BCIS accounts for only approximately $13 \%$ of all breast cancer diagnoses (Fracheboud et al, 2004). Thus, given the same AER, the absolute number of second cancers after BCIS will be considerably smaller than that after invasive breast cancer at the population level. Lastly, no individual data were available on risk factors for cancer (Soerjomataram et al, 2005b). Hence, the contribution of these factors to the risk of second cancer could not be assessed.

\section{Risk pattern}

After the diagnosis of BCIS, there was an increased risk of second breast and skin cancer. The question is whether second malignancies share a common aetiology with the first cancer or whether they are associated with treatment for the first cancer (van Leeuwen and Travis, 2005). It is likely that factors including reproductive characteristics, lifestyle and genetic predisposition such as BRCA2 play a more important role in the excess risk of both second breast and skin cancer after BCIS (Arver et al, 2000; Goggins et al, 2004). We did not find an increased risk of second ovarian cancer among BCIS patients as in patients with malignant breast cancer. However, most patients in this study had less than 10 years of follow-up and the risk of ovarian cancer after breast cancer was highest after more than 15 years of follow-up (Soerjomataram et al, 2005b). 
A

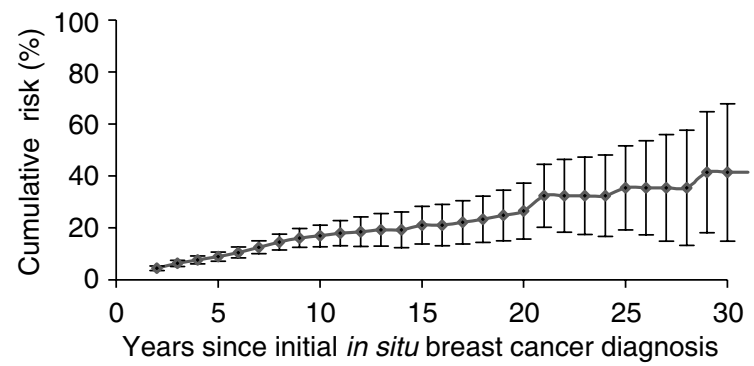

$\begin{array}{lllllll}\text { No. at risk } 1223 & 734 & 242 & 95 & 48 & 25 & 10\end{array}$

B

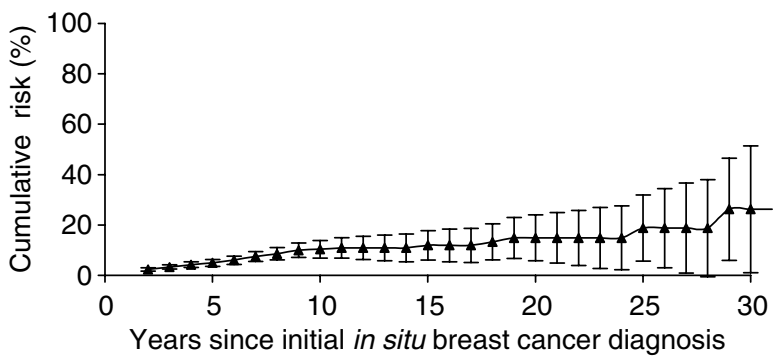

$\begin{array}{lllllll}\text { No. at risk } 1223 & 734 & 242 & 95 & 48 & 25 & 10\end{array}$

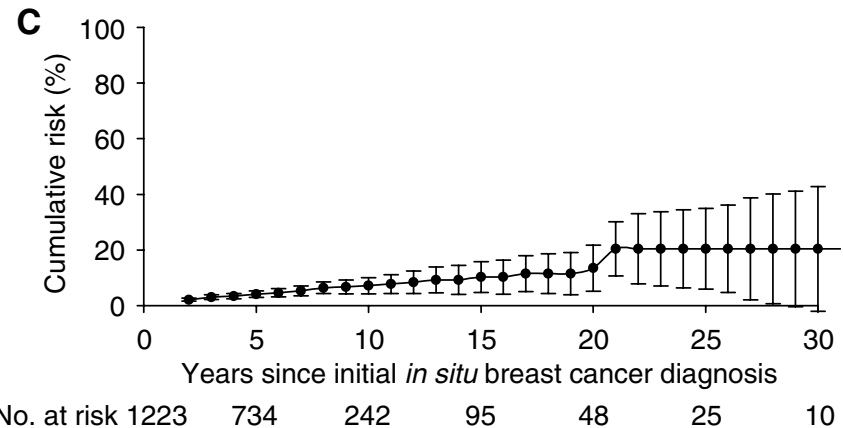

Figure I Cumulative risk of second cancer after the diagnosis of carcinoma in situ of the breast: $(\mathbf{A})$ all sites, $(\mathbf{B})$ breast cancer, $(\mathbf{C})$ other sites excluding breast. No. at risk represented patients still at risk at the beginning of each period.

\section{Determinants}

Age Age at the time of BCIS diagnosis did not seem to influence the risk for second cancer, although we observed a slightly higher risk of second breast cancer among women diagnosed with BCIS before age 50. A higher risk of second breast cancer has been found among in situ and malignant breast cancer patients diagnosed before the age of 50 years (Rawal et al, 2005; Soerjomataram et al, 2005b). This is partly due to genetic predisposition, which usually becomes manifest at a relatively young age.

Treatment The risk for second (ipsi- and contra-lateral) breast and other cancers was slightly higher among BCIS patients who received radiotherapy. Radiation after breast-conserving treatment reduces recurrences in the ipsilateral breast (Fisher et al, 1993;

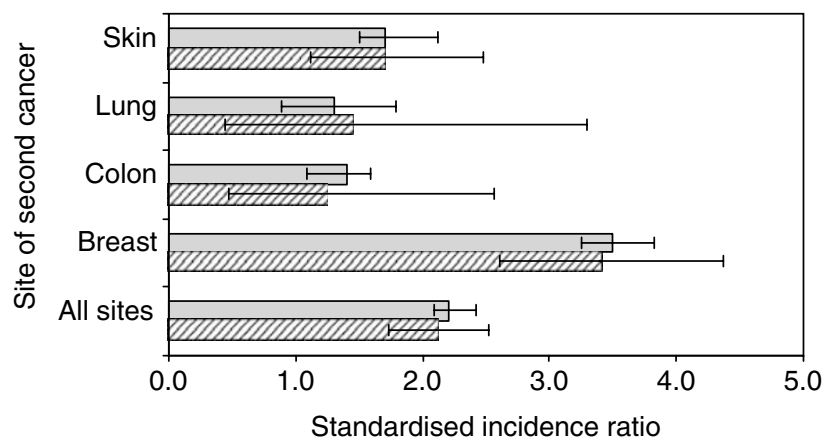

First breast cancer: $\square$ In situ breast cancer $\square$ Invasive breast cancer

Figure 2 Standardised incidence ratio for second cancer among women diagnosed with breast carcinoma in situ and with invasive breast carcinoma (Soerjomataram et al, 2005a).

Julien et al, 2000), but its effect on the risk of new (ipsi- or contralateral) breast cancer is less conclusive (Warnberg et al, 2001; Claus et al, 2003). We found only a slightly increased risk of second breast cancer after radiation that was not significantly different from that of patients without radiotherapy. Thus, the benefit of radiation after surgery for the overall survival of DCIS patients seems to outweigh the increased risk of second breast cancer (Fisher et al, 1993).

Screening The risk of second cancer after BCIS remained elevated and of a similar magnitude after implementation of the national screening policy in the Netherlands. In Sweden, the risk of second breast cancer increased at the beginning of the screening period and only decreased after long implementation of national screening (Rawal et al, 2005). Thus, in the coming decades, we might observe a decrease in the risk of second cancer after BCIS.

\section{Comparison with invasive breast cancer cohort}

The pattern of second cancer after BCIS seems to be similar to that after malignant breast cancer. Cancers of the colorectum, ovarium, lung and skin were some of the most common cancers in women previously diagnosed with an invasive breast cancer (Soerjomataram et al, 2005a). In the USA, colorectal, cervical and endometrial cancer were reported as the most prevalent cancers among BCIS patients (Ward et al, 1992). Thus, we could probably expect an increased incidence of second cancers resembling that of malignant breast cancer within a larger study population and a longer follow-up of BCIS cases.

In conclusion, we found increased relative and absolute risks of second cancer after BCIS diagnosis, similar to that after invasive breast cancer. Monitoring for these breast cancers should therefore be conducted in both the ipsilateral and the contralateral breast.

\section{ACKNOWLEDGEMENTS}

We thank MBCJE Tutein Nolthenius-Puylaert, $M D$ and $M$ Avendano, MPH, MSc for their comments. I Soerjomataram is funded by Comprehensive Cancer Centre South.

\section{REFERENCES}

Arver B, Du Q, Chen J, Luo L, Lindblom A (2000) Hereditary breast cancer: a review. Semin Cancer Biol 10: $271-288$
Breslow NE, Day NE (1987) Statistical methods in cancer research. The design and analysis of cohort studies. IARC Sci Publ II: 1-406 
Chen Y, Semenciw R, Kliewer E, Shi Y, Mao Y (2001) Incidence of second primary breast cancer among women with a first primary in Manitoba, Canada. Breast Cancer Res Treat 67: 35-40

Claus EB, Stowe M, Carter D, Holford T (2003) The risk of a contralateral breast cancer among women diagnosed with ductal and lobular breast carcinoma in situ: data from the Connecticut Tumor Registry. Breast 12: $451-456$

Cutler SJ, Ederer F (1958) Maximum utilization of the life table method in analyzing survival. J Chronic Dis 8: 699-712

Fisher B, Costantino J, Redmond C, Fisher E, Margolese R, Dimitrov N, Wolmark N, Wickerham DL, Deutsch M, Ore L, Mamounas E, Poller W, Kavanah M (1993) Lumpectomy compared with lumpectomy and radiation therapy for the treatment of intraductal breast cancer. $N$ Engl J Med 328: 1581 - 1586

Fracheboud J, de Koning HJ, Beemsterboer PM, Boer R, Hendriks JH, Verbeek AL, van Ineveld BM, de Bruyn AE, van der Maas PJ (1998) Nation-wide breast cancer screening in The Netherlands: results of initial and subsequent screening 1990-1995. National Evaluation Team for Breast Cancer Screening. Int J Cancer 75: 694-698

Fracheboud J, Otto SJ, van Dijck JA, Broeders MJ, Verbeek AL, de Koning HJ (2004) Decreased rates of advanced breast cancer due to mammography screening in The Netherlands. Br J Cancer 91: $861-867$

Franceschi S, Levi F, La Vecchia C, Randimbison L, Te VC (1998) Second cancers following in situ carcinoma of the breast. Int J Cancer 77: $392-395$

Goggins W, Gao W, Tsao H (2004) Association between female breast cancer and cutaneous melanoma. Int J Cancer 111: $792-794$

Habel LA, Moe RE, Daling JR, Holte S, Rossing MA, Weiss NS (1997) Risk of contralateral breast cancer among women with carcinoma in situ of the breast. Ann Surg 225: 69-75

Julien JP, Bijker N, Fentiman IS, Peterse JL, Delledonne V, Rouanet P, Avril A, Sylvester R, Mignolet F, Bartelink H, Van Dongen JA (2000) Radiotherapy in breast-conserving treatment for ductal carcinoma in situ: first results of the EORTC randomised phase III trial 10853. EORTC Breast Cancer Cooperative Group and EORTC Radiotherapy Group. Lancet 355: $528-533$
Levi F, Randimbison L, Te VC, La Vecchia C (2005) Invasive breast cancer following ductal and lobular carcinoma in situ of the breast. Int J Cancer 116: $820-823$

Rawal R, Lorenzo Bermejo J, Hemminki K (2005) Risk of subsequent invasive breast carcinoma after in situ breast carcinoma in a population covered by national mammographic screening. Br J Cancer 92: 162-166

Rubino C, de Vathaire F, Shamsaldin A, Labbe M, Le MG (2003) Radiation dose, chemotherapy, hormonal treatment and risk of second cancer after breast cancer treatment. Br J Cancer 89: 840-846

Soerjomataram I, Louwman WJ, de Vries E, Lemmens VE, Klokman WJ, Coebergh JW (2005a) Primary malignancy after primary female breast cancer in the South of the Netherlands, 1972-2001. Breast Cancer Res Treat 93: $91-95$

Soerjomataram I, Louwman WJ, Lemmens VE, de Vries E, Klokman WJ, Coebergh JW (2005b) Risks of second primary breast and urogenital cancer following female breast cancer in the South of The Netherlands, 1972 - 2001. Eur J Cancer 41: 2331 - 2337

van Leeuwen FE, Travis LB (2005) Second cancers. In Cancer: Principles \& Practices of Oncology, DeVita VTJ, Hellman S, Rosenberg AS (eds), Vol 2, pp 2575 - 2602. Philadelphia: Lippcott-Ravens Publishers

Vereniging van Integrale Kankercentra (2005) Mammacarcinoom Landelijke richtlijn versie 3.0. [Association of Comprehensive Cancer Centres (2005) National guidelines for breast carcinoma version 3.0]

Voogd AC, Crommelin MA, Repelaer van Driel OJ, Nolthenius-Puylaert MC, van der Heijden LH, Coebergh JW (2000) Trends in incidentie en behandelbeleid van ductaal carcinoma in situ van de mamma in Zuidoost-Nederland (Trends in incidence and treatment of ductal carcinoma in situ of the breast in Southeast Netherlands). Ned Tijdschr Geneeskd 144: 659-663

Ward BA, McKhann CF, Ravikumar TS (1992) Ten-year follow-up of breast carcinoma in situ in Connecticut. Arch Surg 127: 1392-1395

Warnberg F, Bergh J, Zack M, Holmberg L (2001) Risk factors for subsequent invasive breast cancer and breast cancer death after ductal carcinoma in situ: a population-based case-control study in Sweden. Cancer Epidemiol Biomarkers Prev 10: 495-499

Warnberg F, Yuen J, Holmberg L (2000) Risk of subsequent invasive breast cancer after breast carcinoma in situ. Lancet 355: 724-725 